\title{
HIS COLOR SPACE TRANSFORMATION FOR DETECTION OF "PISANG MAS" MATURITY BASED ON THE SKIN COLOR
}

\author{
Jan William Sianturi ${ }^{1}$, Bagas Aji Wicaksono ${ }^{2}$, Anindia Adyutawati Nugraheni ${ }^{3)}$, \\ Robertus Bintoro ${ }^{4)}$, Agnes Widianingsih Wulandari ${ }^{5)}$, Kristophorus Abel Priambodo \\ Lumbantobing ${ }^{6}$
}

Teknik Informatika, Fakultas Sains dan Teknologi, Universitas Sanata Dharma Kampus III USD Paingan, Maguwoharjo, Depok, Sleman, Yogyakarta Email : ${ }^{1}$ william_sianturi@yahoo.com

\begin{abstract}
Banana is one of the favorite foods in Indonesia, one type of banana that is quite popular is Pisang Mas. Sometimes consumers have difficulty expressing the maturity of bananas at this time. Image processing can be one way to overcome this problem. In this study we will process documented banana images using a method used to change HIS space to extract the characteristics of banana skin color. The characteristic that is taken is the center of the image of a banana that is experienced as much as $15 x 15$ pixels. Images of bananas are 20 pictures for ripe bananas and 20 pictures of raw bananas. The level of success in this study resulted in a value of $100 \%$.
\end{abstract}

Keyword: HIS, detection, color

\section{Pendahuluan}

Pisang (Musa Paradisiaca) merupakan salah satu buah yang cukup mudah ditemukan dan merupakan salah satu buah yang cukup digemari di Indonesia. Pisang kaya akan kalium, magnesium, besi, fosfor dan kalsium yang dapat diserap tubuh dengan baik. Pisang juga mengandung vitamin A, B, dan B6 yang sangat bermanfaat untuk kesehatan jantung, pengontrol tekanan darah, serta yang tidak kalah penting adalah untuk kelancaran fungsi otak. Banyak jenis pisang yang dapat dijumpai di Indonesia seperti pisang ambon, pisang kepok, pisang mas, dan masih banyak lagi [1][2].

Pisang mas (Musa sinensis) merupakan jenis pisang yang lebih manis dibandingkan dengan jenis pisang lainnya, hal ini disebabkan oleh kandungan gula yang dimiliki oleh buah pisang mas lebih banyak jika dibandingkan dengan buah pisang lainnya [1]. Pada saat matang, warna kulit pisang mas akan berwarna kuning, dan berwarna hijau muda saat masih mentah. Pisang ini memiliki ukuran yang cukup kecil hanya berdiameter sekitar 3-4 cm. Karena ukurannya yang cukup kecil sehingga dapat disantap dalam satu atau dua kali gigitan, maka pisang ini banyak digunakan dalam sajian pelengkap makan. Kadang-kadang sekalipun kulit pisang sepertinya berwarna terang, namun ketika disantap ternyata masih terasa keras atau dengan kata lain masih belum siap untuk disajikan. Karena itulah maka paper ini mencoba menyajikan hasil penelitian untuk mendeteksi kematangan pisang mas dari warna kulitnya.

Dalam pengertian secara umum, biasanya orang menyebut citra dengan gambar. Adapun pengertian yang lebih khusus dari citra (image) adalah suatu representasi (gambaran), kemiripan atau imitasi dari suatu objek pada bidang dua dimensi sebagai keluaran suatu sistem perekam data optik berupa foto, yang bersifat analog atau digital. Pengertian sederhana dari citra adalah citra merupakan suatu kumpulan titik yang dinamakan piksel (pixel atau picture element) [3]. Teknologi pengolahan citra memungkinkan untuk 
dilakukannya pengembangan alat pendeteksi tingkat kematangan buah yang dapat diperoleh dari fitur warna kulit dari setiap citra pisang. Evaluasi mutu ataupun kematangan buah dengan cara mengamati secara visual mempunyai beberapa kelemahan, antara lain membutuhkan waktu lama dan menghasilkan produk dengan mutu yang tidak konsisten karena keterbatasan visual manusia, kelelahan, dan adanya perbedaan persepsi tentang mutu pada masing-masing pengamat [4]. Pengolahan citra merupakan alternatif untuk mengatasi masalah tersebut. Untuk mengenali suatu citra, diperlukan adanya ekstraksi ciri. Ekstraksi ciri dapat diteliti dengan mengambil beberapa bagian citra yang bisa menunjukan ciri khas dari citra tersebut, misalkan warna, pola citra, diameter, bentuk dan masih banyak lagi. [5] Menggunakan metode transformasi ruang warna HIS (Hue, Intensity and Saturation) untuk melakukan ekstraksi ciri, ruang warna dapat digunakan sebagai cara untuk mengatur, membuat dan memvisualisasikan warna [6]. Metode Transformasi Ruang Warna HIS adalah metode yang digunakan untuk melakukan pengubahan terhadap representasi warna dari RGB (Red, Green and Blue) menjadi representasi warna HIS, dimana Hue menyatakan warna sebenarnya dari suatu warna, Saturation menyatakan tingkat kemurnian warna atau dengan kata lain merepresentasikan tentang seberapa banyak warna putih yang terkandung pada warna tersebut dan Intensity yang menyatakan banyaknya cahaya yang diterima mata saat melihat warna tersebut [7].

Sebelumnya, berbagai penelitian juga telah dilakukan para peneliti bidang informatika mengenai buah pisang, seperti pemrosesan citra digital untuk klasifikasi mutu buah pisang menggunakan jaringan saraf tiruan yang berhasil melakikan klasifikasian mutu buah pisang dengan tingkat akurasi 94\% dari total 100 data uji [8]. Selain itu, Indarto dan Murinto juga sudah melakukan penelitian mengenai pendeteksian kematangan buah pisang ambon menggunakan metode transformasi ruang warna HIS dengan tingkat akurasi pengdeteksian kematangan buah pisang sebesar 85\% [9]. Jurnal lainnya yang membahas tentang pendeteksian kematangan buah pisang juga telah dilakukan juga oleh Bere, Tamatjita dan Kusumaningrum menggunakan metode HIS untuk ekstraksi ciri dan K-Nearest Neighbors untuk klasifikasi dengan hasil akurasi yang didapat yaitu : pada kelas sangat matang sebesar $100 \%$, kelas busuk sebesar $66,67 \%$, kelas mengkal $60 \%$ dan kelas matang sebesar $60 \%$, untuk pengujianberdasarkan $\mathrm{k}=3$. Selanjutnya untuk pengujian berdasarkan $\mathrm{k}=1$ pada kelas sangat matangsebesar 100\%, kelas busuk sebesar 66,67\%, kelas mengkal sebesar 66,67\% dan kelas matangsebesar 56,67\% [10] dengan menggunakan pisang Sunpride sebagai objek penelitian. Penelitian ini memaparkan hasil penelitian dalam mengimplementasikan metode transformasi ruang warna HIS untuk pendeteksian kematangan buah pisang mas.

\section{Metodologi Penelitian}

Penelitian ini dimulai dari tahapan pengumpulan data. Data yang digunakan adalah 40 citra pisang yang terdiri dari 20 citra pisang matang dan 20 citra pisang mentah. Data tersebut diperoleh dari pemotretan pisang yang diletakkan di atas kertas HVS putih berukuran A4. Jarak pengambilan gambar adalah $15 \mathrm{~cm}$ dan menggunakan smartphone bermerk Samsung J7 Prime dengan resolusi kamera sebesar 13.0 megapixel. Untuk mengimplementasikan algoritma yang dibangun, digunakan perangkat lunak Matlab versi 2014b.

Untuk membangun sistem pengenalan kulit buah pisang, digunakan metode deteksi seperti terlihat pada Gambar 1. 


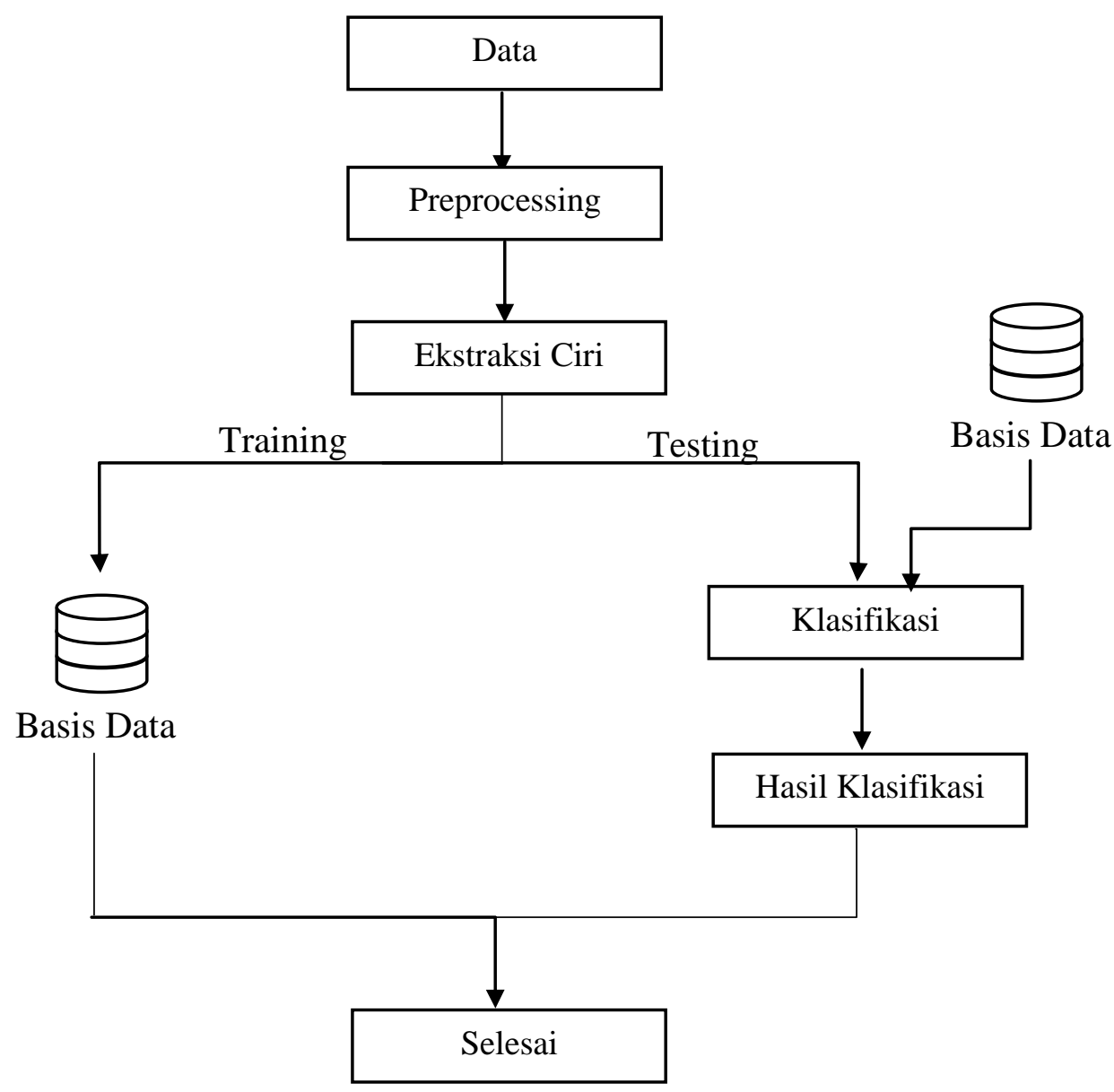

Gambar 1. Diagram Blok Pengembangan Sistem Deteksi Kematangan

Terdapat beberapa langkah untuk mendeteksi kematangan kulit pisang seperti di Gambar 1, yaitu :

1. Capture data untuk mendapatkan citra pisang yang akan diinputkan ke dalam sistem.

2. Tahap Preprocessing yang akan memproduksi citra pisang yang lebih siap untuk diekstraksi ciri, yang terdiri dari:

a. Mengubah ukuran citra (resize) menjadi berukuran 422 x 228 pixel, seperti ditunjukkan pada Gambar 2.
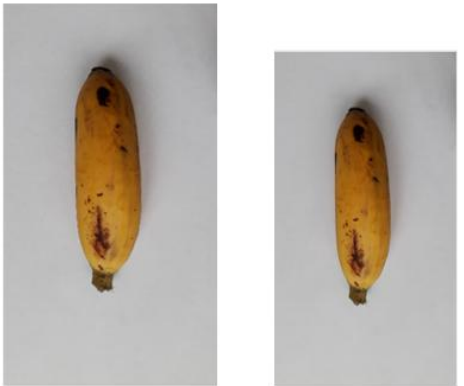

Gambar 2. Citra diubah menjadi berukuran 422x 228 pixel 
b. Segmentasi citra pisang untuk memisahkan latar belakang dari citra pisangnya, dengan mempergunakan metode profil proyeksi, seperti terlihat pada Gambar 3.
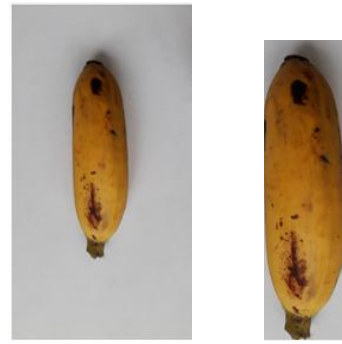

Gambar 3. Contoh hasil segmentasi citra pisang

c. Mengambil luasan citra pisang berukuran $15 \times 15$ pixel yang berada tepat ditengah-tengah citra pisang, seperti digambarkan pada pada Gambar 4.

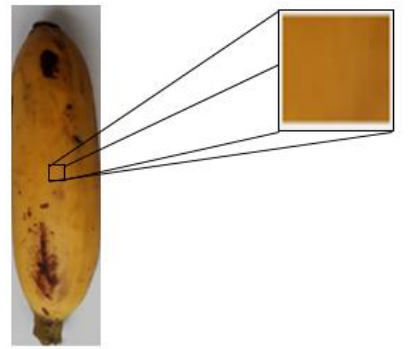

Gambar 4. Ilustrasi pengambilan $15 \times 15$ pixel tengah citra

3. Tahap Ekstraksi Ciri yang akan menghitung nilai rata-rata (I) dari citra tengah untuk setiap layer RGB, yang kemudian ditransformasikan kedalam ruang warna HIS mempergunakan rumus (1) [3].

$$
I \text { (intensity) }=\frac{1}{3}(R+G+B)
$$

Langkah selanjutnya adalah menghitung range nilai $\mathrm{H}$ dan $\mathrm{S}$ untuk citra pisang matang dan citra pisang mentah mempergunakan rumus (2) dan (3)[3].

$$
h(\text { hue })=\left\{\begin{array}{c}
0, \quad \text { jika max }=\text { min } \\
60^{\circ} \times\left(\frac{G-B}{\max -\min } \bmod 6\right), \text { jika } \max =R \\
60^{\circ} \times\left(\frac{B-R}{\max -\min }+2\right), \text { jika } \max =G \\
60^{\circ} \times\left(\frac{R-G}{\max -\min }+4\right), \quad \text { jika } \max =B
\end{array}\right.
$$

Keterangan :

$\mathrm{H}$ : Hue

$\mathrm{R} \quad$ : Rata-rata nilai 15 pixel tengah citra pada lapisan 1 (lapisan Red)

G : Rata-rata nilai 15 pixel tengah citra pada lapisan 2 (lapisan Green)

B : Rata-rata nilai 15 pixel tengah citra pada lapisan 3 (lapisan Blue) 
$\max$ : Nilai tertinggi dari nilai $R, G$ dan $B$

min : Nilai terendah dari nilai $R, G$ dan $B$

$$
s(\text { saturation })=\left\{\begin{array}{l}
0, j i k a \max =\min \\
1-\frac{\min }{I}
\end{array}\right.
$$

Keterangan :

$$
\begin{array}{ll}
\mathrm{S} & \text { : Saturation } \\
\mathrm{I} & \text { : Intensity } \\
\max & \text { : Nilai tertinggi dari nilai R, G dan B } \\
\min & \text { : Nilai terendah dari nilai R, G dan B }
\end{array}
$$

\section{Hasil dan Pembahasan}

Penelitian ini menggunakan data dari 40 citra pisang, 20 citra merupakan citra pisang mentah serta 20 citra lainnya merupakan citra pisang matang dengan format *.jpg. Citra tersebut dimbil 15 pixel tengahnya dan kemudian dihitung rata-rata dari setiap layer RGB kemudian ditransformasikan menjadi ruang warna HSI. Adapun data dibagi menjadi 2 bagian yaitu training dan testing, dimana $2 / 3$ dari setiap data digunakan sebagai data training dan $1 / 3$ bagian lainnya digunakan sebagai data testing. Sehingga 13 citra akan digunakan sebagai data training dan 7 citra akan digunakan sebagai data testing untuk setiap jenis pisang. Berikutnya adalah mencari nilai terkecil dan terbesar untuk nilai $\mathrm{H}, \mathrm{S}$ dan I untuk setiap citra pisang baik mentah maupun matang yang nantinya akan mendapatkan range nilai untuk tahap klasifikasi nantinya.

Tabel 1. menunjukkan nilai HSI yang diperoleh dari hasil transformasi ruang warna dari RGB menjadi ruang warna HSI untuk setiap jenis citra pisang baik mentah maupun matang.

Tabel 1. Nilai HSI Setiap Citra Pisang

\begin{tabular}{|c|c|c|c|c|c|c|}
\hline \multirow{2}{*}{$\begin{array}{c}\text { Data } \\
\text { Citra }\end{array}$} & \multicolumn{2}{|c|}{ Warna Kulit Matang } & \multicolumn{3}{c|}{ Warna Kulit Mentah } \\
\cline { 2 - 7 } & $\mathbf{H}$ & $\mathbf{S}$ & $\mathbf{I}$ & $\mathbf{H}$ & $\mathbf{S}$ & $\mathbf{I}$ \\
\hline 1 & 33,9250 & 0,7541 & 0,4029 & 61,6435 & 0,5041 & 0,4308 \\
\hline 2 & 35,4613 & 0,8455 & 0,3901 & 65,5409 & 0,5778 & 0,3163 \\
\hline 3 & 34,2815 & 0,9165 & 0,3461 & 65,3493 & 0,5398 & 0,3838 \\
\hline 4 & 35,5217 & 0,7877 & 0,4089 & 61,9703 & 0,5040 & 0,4551 \\
\hline 5 & 36,7877 & 0,7545 & 0,4305 & 64,0168 & 0,5452 & 0,3929 \\
\hline 6 & 36,5455 & 0,8896 & 0,4043 & 63,0785 & 0,6492 & 0,2600 \\
\hline 7 & 37,4199 & 0,7759 & 0,4428 & 62,6340 & 0,5634 & 0,3083 \\
\hline 8 & 35,8720 & 0,8418 & 0,3845 & 64,5033 & 0,6098 & 0,3013 \\
\hline 9 & 36,0090 & 0,7662 & 0,4229 & 65,5340 & 0,5885 & 0,3683 \\
\hline 10 & 36,4575 & 0,7764 & 0,4209 & 62,4707 & 0,5086 & 0,4314 \\
\hline 11 & 38,8013 & 0,8142 & 0,4432 & 60,1594 & 0,4852 & 0,4502 \\
\hline 12 & 37,3025 & 0,8061 & 0,4349 & 65,0453 & 0,6480 & 0,2596 \\
\hline 13 & 35,2070 & 0,7752 & 0,4027 & 62,6081 & 0,5100 & 0,4220 \\
\hline
\end{tabular}


Nilai H, S dan I setiap citra pisang baik matang maupun mentah kemudian dicari nilai terbesar dan terkecilnya, sehingga diperoleh data seperti terlihat pada Tabel 2.

Tabel 2. Range Nilai HSI Citra Pisang Matang dan Mentah

\begin{tabular}{|c|c|c|c|c|c|c|c|c|c|c|c|}
\hline \multicolumn{4}{|c|}{ Matang } & \multicolumn{5}{c|}{ Mentah } \\
\hline \multicolumn{2}{|c|}{ H } & \multicolumn{2}{|c|}{ S } & \multicolumn{2}{c|}{ I } & \multicolumn{2}{c|}{ H } & \multicolumn{2}{c|}{ S } & \multicolumn{3}{c|}{ I } \\
\hline Min & Max & Min & Max & Min & Max & Min & Max & Min & Max & Min & Max \\
\hline 33.925 & 38.801 & 0.7540 & 0.9165 & 0.3461 & 0.4432 & 60.159 & 65.540 & 0.4852 & 0.6492 & 0.2596 & 0.4550 \\
\hline
\end{tabular}

Dari data pada Tabel 2, dapat dilihat bahwa range nilai I yang didapat pada jenis pisang matang maupun mentah berada pada range nilai yang saling berhimpitan, yang mengakibatkan nilai I tersebut tidak digunakan dalam klasifikasi. Dari Tabel 2. tersebut dapat disimpulkan bahwa sebuah citra pisang dapat dinyatakan sebagai pisang mentah jika memiliki nilai H diantara $60.159-65.540$ dan nilai S diantara $0.4852-0.6492$. Sedangkan untuk pisang matang memiliki nilai $\mathrm{H}$ diantara 33.925-38.801 dan nilai $\mathrm{S}$ diatara 0.75400.9165.

Pengujian sistem dilakukan dengan membandingkan nilai $\mathrm{H}$ dan $\mathrm{S}$ yang dimiliki oleh citra pisang pada range matang, sehingga sistem akan memprediksi bahwa citra tersebut merupakan citra pisang matang dan sebalikknya. Pengujian dilakukan dengan menggunakan 14 buah data citra yang diambil masing-masing 7 untuk setiap jenis citra pisang. Dari hasil pengujian pada 14 data citra uji, diperoleh data seperti terlihat pada Tabel 3. Berdasarkan data pada Tabel 3., dapat disimpulkan bahwa sistem dapat melakukan klasifikasi dengan sangat baik, yaitu dengan akurasi sebesar $100 \%$.

Tabel 3. Hasil Klasifikasi Data Testing

\begin{tabular}{|c|c|c|c|c|c|c|c|}
\hline Citra & 15 pixel tengah & $\mathbf{H}$ & $\mathbf{S}$ & Range $H$ & Range S & Kenyataan & Sistem \\
\hline 1 & & 36,3413 & 0,7843 & \multirow{7}{*}{$\begin{array}{l}w \\
w \\
\text { w } \\
\text { w } \\
1 \\
w \\
\infty \\
\infty \\
0\end{array}$} & \multirow{7}{*}{$\begin{array}{l}0 \\
\dot{u} \\
t \\
0 \\
1 \\
\dot{0} \\
\dot{0} \\
\vec{a}\end{array}$} & Matang & Matang \\
\hline 2 & & 37,5099 & 0,7347 & & & Matang & Matang \\
\hline 3 & & 36,3133 & 0,9126 & & & Matang & Matang \\
\hline 4 & & 33,1121 & 0,7868 & & & Matang & Matang \\
\hline 5 & & 36,4768 & 0,9104 & & & Matang & Matang \\
\hline 6 & & 35,0250 & 0,8286 & & & Matang & Matang \\
\hline 7 & & 36,6455 & 0,8933 & & & Matang & Matang \\
\hline 8 & & 61,9811 & 0,5241 & \multirow{4}{*}{ 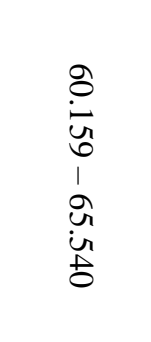 } & \multirow{4}{*}{ 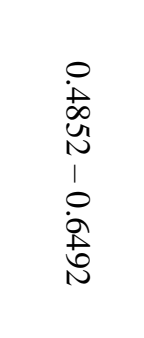 } & Mentah & Mentah \\
\hline 9 & & 52,0354 & 0,5686 & & & Mentah & Mentah \\
\hline 10 & & 64,0445 & 0,5260 & & & Mentah & Mentah \\
\hline 11 & & 59,4789 & 0,5001 & & & Mentah & Mentah \\
\hline
\end{tabular}




\begin{tabular}{|c|c|c|c|c|c|c|c|}
\hline Citra & 15 pixel tengah & H & S & Range H & Range S & Kenyataan & Sistem \\
\hline 12 & & 60,5283 & 0,4769 & & & Mentah & Mentah \\
\cline { 1 - 4 } 13 & & 60,9757 & 0,4909 & & & Mentah & Mentah \\
\cline { 1 - 4 } 14 & & 58,8001 & 0,5080 & & & Mentah & Mentah \\
\hline
\end{tabular}

\section{Kesimpulan}

Berdasarkan pada hasil pengujian sistem deteksi kematangan buah pisang, dapat disimpulkan bahwa kematangan buah pisang dapat dikenali dari warna kulitnya dengan menggunakan metode transformasi ruang warna HIS.

\section{Ucapan Terimakasih}

Terima kasih kepada Universitas Sanata Dharma (USD) yang memberikan bantuan dana sehingga penelitian dan deseminasi hasil penelitian bersama mahasiswa Teknik Informatika USD dapat dilaksanakan

\section{Daftar Pustaka}

[1] Nurhayati, Tamtarini, Jayus, Ruriani, E., Hidayati, L.N. (Tanpa Tahun). Sifat-Sifat Prebiotik Ripe Banana Chip (RBC) Musa Sinensis.

online :

http://download.portalgaruda.org/article.php?article=376045\&val=1574\&title=SIFAT-

SIFAT\%20PREBIOTIK\%20RIPE\%20BANANA\%20CHIP\%20(RBC)\%20Musa\%20si nensis. Diakses 10 November 2018.

[2] Simangunsong, A. (2017) Eksplorasi dan Karakterisasi Pisang Mas (Musa Spp) di Kabupaten Nganjuk, Mojokerto, Lumajang Dan Kediri. Jurnal Produksi Tanaman, 5(3, pp. $363-367)$.

[3] Kadir, A. dan Susanto, A. (2013). Teori dan Aplikasi Pengolahan Citra. Yogyakarta : Andi Publisher.

[4] Prahudaya, T. Y., \& Harjoko, A. (2017). Metode Klasifikasi Mutu Jambu Biji Menggunakan Knn Berdasarkan Fitur Warna Dan Tekstur. Jurnal Teknosains, 6(2, pp. 113).

[5] Manik, F. Y., \& Saragih, K. S. (2017). Klasifikasi Belimbing Menggunakan Naïve Bayes Berdasarkan Fitur Warna RGB. IJCCS (Indonesian Journal of Computing and Cybernetics Systems), 11(1, pp. 99).

[6] Ford, A., \& Roberts, A., (1998), Colour Space Conversions. online : https://poynton.ca/PDFs/coloureq.pdf, Diakses 4 November 2018.

[7] Swedia, E. (2010). Algoritma Transformasi Ruang Warna. online: http://margi.staff.gunadarma.ac.id/Publications/files/2617/Pengolahan+Citra++Algoritma+Transformasi+Ruang+Warna.pdf Diakses 4 November 2018.

[8] Wijaya, Y. \& Harjoko, A. (2014). Pemrosesan Citra Digital untuk Klasifikasi Mutu Buah Pisang Menggunakan Jaringan Saraf Tiruan. IJEIS, 4(1, pp. 57-68).

[9] Indarto \& Murinto (2017). Deteksi Kematangan Buah Pisang Berdasarkan Fitur Warna Citra Kulit Pisang Menggunakan Metode Transformasi Ruang Warna HIS. JUITA 5(1).

[10] Bere, G. A., Tamatjita, E. N., \& Kusumaningrum, A. (2016,November). Klasifikasi Untuk Menentukan Tingkat Kematangan BuahPisang Sunpride. SENATIK (2, pp. 109-113). 